\title{
Una notable convergencia semántica: infección y miasma
}

\author{
Carlos G. Osorio
}

\section{A remarkable semantic convergence: infection and miasma}

The historical development of the terms "infection" and "miasma" is analyzed. Miasma was understood as a kind of corrupt or pestilent air that emanated from putrefactive bodies and spread infectious diseases. This concept was the dominant one to understand the cause of infectious diseases from antiquity to the dawn of the microbial theory. The concept of infection initially had a similar meaning to miasma, but is currently defined as the invasion of a host by an infectious agent. It will be discussed in this paper that both terms derive from the same original concept.

Key words: Infection; miasma; history of medicine.

Palabras clave: Infección; miasma; historia de la medicina.

\section{Introducción}

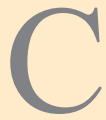
uando se lee la memoria del licenciado Dr. Rafael Wormald sobre "La podredumbre o gangrena de hospital" publicada en 1852, se indica en uno de sus párrafos: "Todas estas circunstancias son mui adecuadas para producir la corrupción del aire en que se hallan los heridos i alterada la atmósfera de este modo por las exhalaciones concentradas de tantos hombres...". En otro párrafo se expresa: "Es sobre todo temible la infección miasmática del aire cuando los heridos están ya enfermos de antemano...". Estas pocas líneas expresan claramente la concepción que se tenía en dicha época sobre el término miasma como aire corrupto o putrefacto que emanaba de las heridas o cadáveres. Es destacable que el segundo párrafo hable de "infección miasmática del aire" indicando la idea de que el aire corrupto debido a la concentración de miasmas o exhalaciones podía transportar la infección desde pacientes enfermos a otros sanos. El siguiente párrafo del informe del Dr. Manuel Antonio Carmona sobre una epidemia en Valparaíso es esclarecedor sobre este último punto: "He dicho que el contagio general es un humor o efluvio vicioso, emanado de un ser viviente enfermo, i que ocasiona en otro idéntica enfermedad, transmitiéndole el principio contagioso por el conducto del aire...". Varios médicos de esa época utilizaron una terminología similar a la citada anteriormente en sus ensayos o memorias sobre enfermedades infecciosas publicados en los Anales de la Universidad de Chile $^{3}$. Pero ¿cuál es el origen del término miasma?

\section{Origen del término miasma}

Miasma (plural miasmata) era un sustantivo griego que derivó del verbo miaino cuyo significado era "teñir" o "manchar". En sus inicios fue utilizado en varias tragedias griegas clásicas de los dramaturgos Esquilo, Sófocles y Eurípides en un contexto religioso o legal. La idea original era que una persona que cometía un asesinato o tenía una conducta sacrílega quedaba manchada o teñida por la sangre derramada por dicho acto y debía ser purificada ${ }^{4}$. Por ejemplo, en la tragedia de Esquilo (525-456 a. C.) titulada "Los siete contra Tebas" se dice: "Pero la muerte de dos hermanos que entre ellos se matan así, con sus propias manos..., esta mancha (miasmatos) no perecerá". En la tragedia "Las suplicantes de Esquilo" se lee lo siguiente: "la tierra irritada de verse manchada (miasmasin) con la impureza de la sangre derramada en crimenes antiguos...". Finalmente, en la tragedia de Eurípides (480-406 a. C.), titulada "Medea", también se
Universidad de Chile, Santiago, Chile. Facultad de Medicina, Programa de Microbiología y Micología, Instituto de Ciencias Biomédicas (ICBM).

No existen conflictos de interés Fuente de financiamiento: no corresponde.

Recibido: 6 de noviembre de 2017

Correspondencia a: gonosorio@med.uchile.c

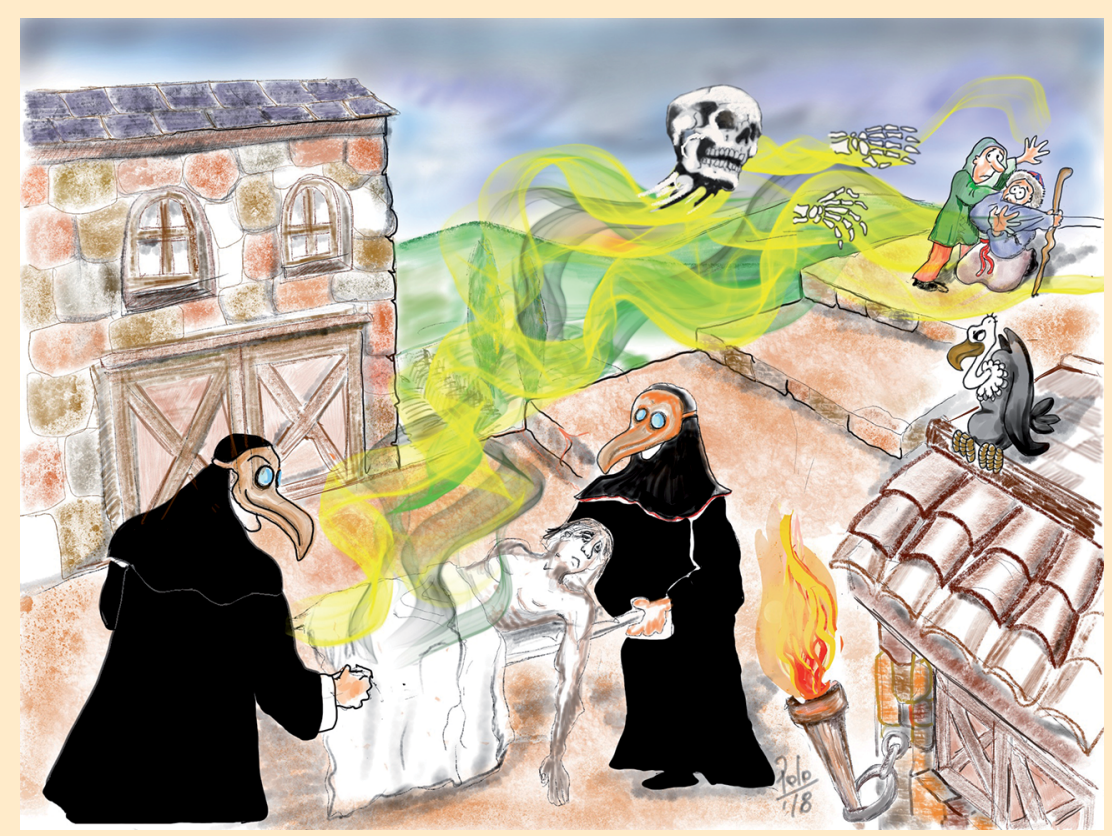


utiliza la misma palabra: “Desdichada, ¿qué cólera cruel se ha apoderado de tu corazón y en él infunde el furor del asesinato? Unas manchas (miasmata) fatales son para los mortales derramar por la tierra sangre de allegados...". También aparece la palabra en otras obras de autores griegos destacados, tales como: La República y las Leyes de Platón, Descripción de Grecia de Pausanias, Historias de Polibio, Discursos de Demóstenes y varios otros ${ }^{5}$.

\section{Miasma y enfermedad}

La idea original de estar manchado o impuro por un pecado cometido cambia su sentido en el contexto médico, transformando lentamente su significado a la idea de una persona enferma o "infectada". El primer paso en esta metamorfosis fue establecer una relación entre la palabra miasma y ciertas patologías. Esto ocurrió en al menos dos casos bien documentados. Primeramente, se relacionó miasma con una epidemia que afectó a la ciudad de Tebas. El dramaturgo Sófocles (496-406 a. C.) en su obra Edipo Rey dice: "la más odiosa pestilencia (peste) descendió sobre la ciudad; debido a ella, la casa de Cadmo está vacía..." 4,5 . Posteriormente el oráculo de Delfos anunció a los tebanos por medio del rey Creón lo siguiente: "Te diré lo que escuché del dios. Febo, nuestro señor, claramente nos ordena que eliminemos la contaminación (miasma) que dijo que estaba albergada en esta tierra...". El miasma que afectaba a la ciudad de Tebas se debía al asesinato del antiguo rey. El otro caso que muestra claramente esta nueva relación aparece en la obra hipocrática "Sobre la enfermedad sagrada". En ella se expresa lo siguiente: "Ellos purifican a los afectados por la enfermedad (epilepsia) con sangre y otras cosas similares, como las usadas en personas afectadas por un miasma..." 4,5 .

\section{Miasma en los tratados hipocráticos}

La relación establecida entre miasma y enfermedad llevó finalmente a que el razonamiento patológico avanzara más allá y planteara expresamente que las personas que adquirían la enfermedad lo hacían inhalando los miasmas contenidos en el aire circundante. En otras palabras, la mancha o impureza original intangible e inmaterial se transformó en un ente material y natural que contaminaba el aire respirado. Esta nueva transformación se hace evidente en la obra hipocrática titulada "Sobre los Vientos", en que el autor expresa lo siguiente (capítulo 5): “Inmediatamente después de esto, podemos decir que la fuente de las enfermedades es, con toda probabilidad, el aire, ya sea en mucha cantidad o muy poca o cuando este contiene miasmas morbosos que entran en el cuerpo". En otro párrafo se dice (capítulo 6): “Así, cuando el aire está lleno de miasmas, cuyas propiedades son hostiles a la naturaleza humana, asi es cuando el hombre enferma" (Figura 1).

\section{El término infección}

Por otra parte, en la lengua latina existió el verbo inficio cuyo significado era teñir o manchar (a su vez este verbo derivaba de in-facio, esto es, literalmente hacer o meter dentro), por tanto, equivalente al verbo griego miaino discutido anteriormente. De este verbo latino derivó el participio infectus y el sustantivo infectio. En la literatura latina clásica estos términos fueron lentamente alterando su significado y, por ejemplo, el célebre poeta romano Virgilio los utiliza con la idea de emponzoñar o envenenar (s. I a. C.). Claramente es posible vislumbrar en este cambio un desarrollo semejante al sufrido por la palabra griega miasma. Posteriormente, a fines del s. IV d. C., se constata la clara asociación de infectio con enfermedad. Esto ocurre en una obra de amplia repercusión en Occidente, la traducción latina de la Biblia hebrea y griega por San Jerónimo, denominada "La Vulgata". Se puede leer en esta obra lo siguiente (Lev

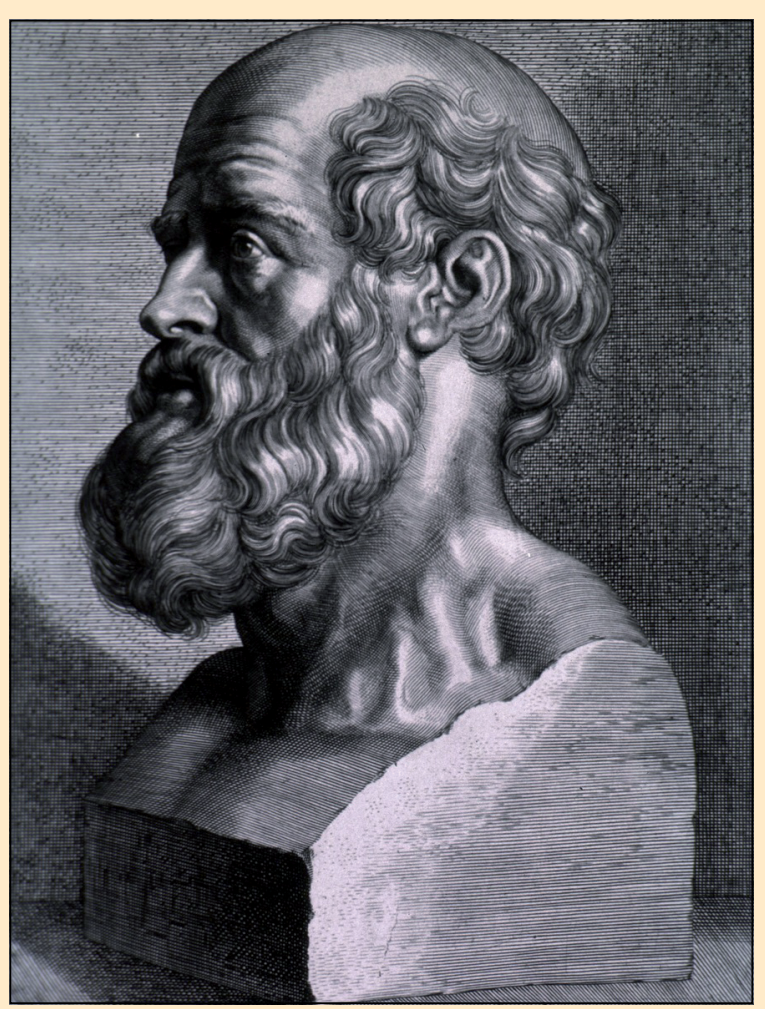

Figura 1. Hipócrates de Cos (Cos, c. 460 a. C.-Tesalia c. 370 a. C.). Médico griego, a quien se conoce como el padre de la Medicina. En su obra "Sobre los Vientos" se utiliza la palabra miasma para designar al agente morboso que movilizándose a través del aire causa enfermedad (Fuente de imagen: Wikipedia 2017). 
13, 49): “...si hubiese una mancha blanca o rojiza en la piel se considerará infección por lepra y se mostrará al sacerdote...". El participio infectus y el sustantivo infectio dieron origen en castellano (s. XV) a los términos "infectado" e "infección"; respectivamente?.

\section{Epílogo}

Cuando se dice actualmente que una persona está cursando una infección o está infectada, se entiende claramente que un microbio invadió sus tejidos y que esto le ha causado una enfermedad infecciosa. El breve recuento histórico esbozado en esta nota evidencia claramente que dichas palabras tienen una historia muy antigua y compleja y que su origen fue totalmente independiente de la actual teoría microbiana. Por otra parte, sorprende la convergencia semántica entre los términos griego miasma y latino infectio, ambos originalmente relacionados con la acción de teñir o manchar y ambos derivando posteriormente a una asociación con enfermedades infecciosas. Al parecer, la idea de que una infección microbiana es similar a una mancha o que estar infectado es como estar manchado es inherente al concepto mismo de infección. Si en el devenir histórico los microbiólogos o infectólogos se hubiesen inclinado por el término griego en vez del latino para denominar las infecciones, perfectamente se podría hoy hablar de un miasma bacteriano en vez de una infección bacteriana y de miasmología en vez de infectología.

\section{Resumen}

Se analiza el desarrollo histórico de los términos "infección” y "miasma". Se entendía por miasma un tipo de aire corrupto o pestilente que emanaba de cuerpos en putrefacción y que propalaba las enfermedades infecciones. Dicho concepto fue el dominante para comprender la causa de las enfermedades infecciosas desde la antigüedad hasta los albores de la teoría microbiana. El concepto de infección tuvo inicialmente un significado similar al de miasma, pero actualmente se define como la invasión de un hospedero por un agente infeccioso. En este trabajo se discutirá que ambos términos derivan del mismo concepto original.

\section{Referencias bibliográficas}

1.- Wormald R. Memoria presentada a la Facultad de Medicina para obtener el grado de Licenciado. AUCH 1852; 9: 405-15.

2.- Carmona M A. Informe médico-legal del facultativo don Manuel Antonio Carmona a la ilustre Municipalidad de Valparaíso, sobre el mismo asunto del precedente discurso i en que se refuta una parte de él. AUCH 1865; 27: 373-83.

3.- Osorio C G. Sobre el origen de la Bacteriología Experimental en Chile. Rev Med Chile 2010; 138: 913-9.

4.- Jouanna J. Capítulo: Air, Miasma and Contagion in the time of Hippocrates and the survival of miasmas in the posthippocratic medicine, En: Greek Medicine from Hippocrates to Galen. 2012; pág: 119-36. Disponible en: http://www. jstor.org/stable/10.1163/j.ctt1w76vxr.12?seq=1\#page_scan_ tab_contents (Fecha de acceso: 3 de octubre de 2017).

5.- Perseus Digital Library. Tufts University. Disponible en: http://www.perseus.tufts.edu/ (Fecha de acceso: 15 de octubre de 2017).

6.- Hippocrates. Breaths, En vol II, Loeb Classical Library, Harvard University Press, Cambridge, MA, USA, 1959; pág: 219-53.

7.- Corominas J. Breve diccionario etimológico de la lengua castellana. Sexta edición, Editorial Gredos SA, Madrid, España, 2012. 